\title{
Relationship between B-type natriuretic peptide levels and echocardiographic indices of left ventricular filling pressures in post-cardiac surgery patients
}

\author{
Alessandro Salustri*1,2, Elena Cerquetani², Mara Piccoli2, \\ Guglielmo Pastena ${ }^{2}$, Alfredo Posteraro ${ }^{2}$, Elisabetta Amici², Salvatore La \\ Carrubba $^{3}$, Sherif Bakir ${ }^{1}$ and Wael Abdulrahman Al Mahmeed ${ }^{1}$
}

Address: ${ }^{1}$ Institute of Cardiac Science, Sheikh Khalifa Medical City, P.O. Box 51900, Abu Dhabi, United Arab Emirates, ${ }^{2}$ Cardiology Department, Policlinico Luigi di Liegro, Via dei Badoer 5, Roma, Italy and ${ }^{3}$ Internal Medicine, Villa Sofia Whitaker Hospital, Piazza Salerno 1, Palermo, Italy

Email: Alessandro Salustri* - asalustri@skmc.gov.ae; Elena Cerquetani - ecerquetani@yahoo.com; Mara Piccoli - mandimara@libero.it; Guglielmo Pastena - willypast@tele2.it; Alfredo Posteraro - alposte@tiscali.it; Elisabetta Amici - amici.elisabetta@virgilio.it; Salvatore La Carrubba - salvatore.lacarrubba@tiscali.it; Sherif Bakir - sbakir@skmc.gov.ae; Wael Abdulrahman Al Mahmeed - walmahmeed@skmc.gov.ae

* Corresponding author

Published: 28 October 2009

Cardiovascular Ultrasound 2009, 7:49 doi:10.1 186/1476-7/20-7-49
Received: 4 September 2009

Accepted: 28 October 2009

This article is available from: http://www.cardiovascularultrasound.com/content/7/1/49

(c) 2009 Salustri et al; licensee BioMed Central Ltd.

This is an Open Access article distributed under the terms of the Creative Commons Attribution License (http://creativecommons.org/licenses/by/2.0), which permits unrestricted use, distribution, and reproduction in any medium, provided the original work is properly cited.

\begin{abstract}
Background: B-type natriuretic peptide (BNP) is increased in post-cardiac surgery patients, however the mechanisms underlying BNP release are still unclear. In the current study, we aimed to assess the relationship between postoperative BNP levels and left ventricular filling pressures in post-cardiac surgery patients.

Methods: We prospectively enrolled 134 consecutive patients referred to our Center $8 \pm 5$ days after cardiac surgery. BNP was sampled at hospital admission and related to the following echocardiographic parameters: left ventricular (LV) diastolic volume (DV), LV systolic volume (SV), LV ejection fraction (EF), LV mass, relative wall thickness (RWT), indexed left atrial volume (iLAV), mitral inflow $\mathrm{E} / \mathrm{A}$ ratio, mitral $\mathrm{E}$ wave deceleration time (DT), ratio of the transmitral $\mathrm{E}$ wave to the Doppler tissue early mitral annulus velocity ( $\left.E / E^{\prime}\right)$.

Results: A total of 124 patients had both BNP and echocardiographic data. The BNP values were significantly elevated (mean $353 \pm 356 \mathrm{pg} / \mathrm{ml}$ ), with normal value in only 17 patients (I3.7\%). Mean LVEF was $59 \pm 10 \%$ (LVEF $\geq 50 \%$ in 108 pts). There was no relationship between BNP and LVEF ( $P$ $=0.1 \mathrm{l})$, LVDV $(p=0.88)$, LVSV $(p=0.50)$, E/A $(p=0.77)$, DT $(p=0.33)$ or RWT $(p=0.50)$. In contrast, BNP was directly related to E/E' $(p<0.001)$, LV mass $(p=0.006)$ and ${ }_{i} L A V(p=0.026)$. At multivariable regression analysis, age and $E / E^{\prime}$ were the only independent predictors of BNP levels.

Conclusion: In post-cardiac surgery patients with overall preserved LV systolic function, the significant increase in BNP levels is related to E/E', an echocardiographic parameter of elevated LV filling pressures which indicates left atrial pressure as a major determinant in BNP release in this clinical setting.
\end{abstract}




\section{Background}

B-type natriuretic peptide (BNP), a cardiac hormone synthesized by ventricular myocytes in response to left ventricular (LV) dysfunction and wall stress, has been shown to be increased in patients with cardiovascular disease such as heart failure, [1] cardiac hypertrophy,[2] and acute coronary syndromes [3]. Although in most of these situations the increase in BNP is related to systolic LV dysfunction [4], recent evidences suggest that, at least in patients with heart failure, elevated LV filling pressures may also act as a trigger for BNP release $[5,6]$ and are likely to reduce exercise capacity [7]. More recently, high levels of BNP have also been reported early after cardiac surgery, with prognostic implications for prolonged hospital stay and 1-year mortality [8]. However, it is worth noting that in post-cardiac surgery patients, as compared to patients with heart failure, LV ejection fraction does not correlate as much as expected with BNP levels [9]. Thus, in this clinical setting, factors other than LV systolic function, such as myocardial damage during aortic cross clamping, have been advocated;[10] however the results of these studies are still controversial and the mechanisms underlying $\mathrm{BNP}$ release remain unclear.

We hypothesized that elevated LV filling pressures in postcardiac surgery patients may account for the increase in plasma BNP. Thus, we designed this prospective study with the aims of assessing the relationship between postoperative BNP levels and LV filling pressures as evaluated by transthoracic two-dimensional and Doppler echocardiography.

\section{Methods}

We prospectively enrolled 134 consecutive in-hospital patients admitted to our Centre for a cardiac rehabilitation program $8 \pm 5$ days after a cardiac surgery procedure. No patients required urgent cardiac surgery due to acute myocardial infarction or acute heart failure. Patients in haemodialysis were excluded. All patients were clinically stable and followed the medical therapy prescribed by the referring physicians.

Participants in the study had complete data on age, sex, diabetes mellitus (glucose level $>126 \mathrm{mg} / \mathrm{dl}$ or hypoglicemic drugs), renal insufficiency (serum creatinine value $\geq 1.5 \mathrm{mg} / \mathrm{dl}$ ), type of cardiac surgery, and length of hospitalization. The investigation conforms with the principles outlined in the Declaration of Helsinki. The hospital institutional review board approved the study and written informed consent to participate in the study was obtained from all patients.

\section{BNP measurements}

Blood samples $(5 \mathrm{ml})$ were obtained 24 hours after patient admission. In all patients, blood was sampled from an antecubital vein after 15 minutes of supine rest and collected into a sampling tube containing potassium EDTA. Samples were analyzed for BNP levels using a microparticle enzyme immunoassay (Abbott Laboratories, Abbott Park, Illinois, USA). The precision and sensitivity of this kit have been previously described by Rawlins et al [11].

\section{Echocardiography}

All the patients underwent a comprehensive echocardiographic study within 24 hours after admission at our Center using a commercially available ultrasound equipment (Philips Sonos 5500, Andover, Massachusetts, USA). All measurements were made according to the recommendations of the American Society of Echocardiography/European Association of Echocardiography [12].

The left ventricular (LV) assessment included measurement of the diastolic (DV) and systolic (SV) volumes with derived ejection fraction (LVEF) using the modified biplane Simpson's method, mass, and relative wall thickness (RWT). Left atrial volume was derived using the modified biplane Simpson's method and the value was indexed by body surface area. Mitral inflow was assessed from the apical 4-chamber view using pulsed-wave Doppler. Early-to-late diastolic velocities (E/A) ratio was calculated, as well as the deceleration time (DT) of the E wave. The early diastolic velocities at the septal and lateral mitral annulus were obtained from the apical 4-chamber view using Doppler tissue imaging, and the values were averaged $\left(E^{\prime}\right)$. LV filling pressure was estimated by the $E / E^{\prime}$ ratio [13].

\section{Statistics}

All analyses were performed by using SPSS for Windows (version 12.0.1, Chicago Ill.). Continuous variables are expressed as mean $\pm \mathrm{SD}$. Categorical variables are expressed as number of subjects and percentages. Since plasma concentrations of BNP did not follow a Gaussian distribution, the values were log-transformed before statistical analysis. We used the independent Student's t test for univariate comparison of log-transformed BNP $[\ln (\mathrm{BNP})]$ value within dichotomic variables. Correlations between continuous variables were tested by Pearson's correlation test. Multiple regression analysis was used to clarify the contribution of each independent variable to BNP having $\ln (\mathrm{BNP})$ as the dependent variable. Statistical significance was assumed at $\mathrm{p}<0.05$.

\section{Results}

Ten patients were excluded because of poor acoustic windows that resulted in incomplete echocardiographic measurements. Thus, a total of 124 patients with BNP and echocardiographic data formed the final group and were included in the analysis (Table 1). 
Table I: Clinical characteristics of the study population.

\begin{tabular}{|c|c|}
\hline Number of patients & 124 \\
\hline Male, nr (\%) & $83(67)$ \\
\hline Age, mean \pm SD (yrs) & $67 \pm 10$ \\
\hline Days after cardiac surgery, mean $\pm S D$ & $8 \pm 5$ \\
\hline \multicolumn{2}{|l|}{ Type of surgery, $\mathrm{nr}(\%)$} \\
\hline - CABG & $67(54)$ \\
\hline - Valve surgery & $39(31)$ \\
\hline - $\mathrm{CABG}+$ valve surgery & II (9) \\
\hline - Aorta replacement & $7(6)$ \\
\hline Renal failure, $\mathrm{nr}(\%)$ & $18(14)$ \\
\hline Diabetes, $\mathrm{nr}(\%)$ & $30(24)$ \\
\hline \multicolumn{2}{|l|}{ Medical therapy, nr (\%) } \\
\hline - betablockers & $72(61)$ \\
\hline - ACE-inhibitors & $81(78)$ \\
\hline$-A R B$ & $15(13)$ \\
\hline - Diuretics & $92(78)$ \\
\hline
\end{tabular}

$\mathrm{ACE}=$ angiotensin converting enzyme; $\mathrm{ARB}=$ angiotensin receptor blockers; $C A B G=$ coronary artery bypass graft.

\section{BNP after cardiac surgery}

Plasma BNP levels were significantly elevated in the study group (range 39-2808 pg/ml; mean $353 \pm 346 \mathrm{pg} / \mathrm{ml}$ ) and only $17(13.7 \%)$ patients had normal BNP levels $(<100$ $\mathrm{pg} / \mathrm{ml})$. After log-transformed, the mean $\ln (\mathrm{BNP})$ was $5.54 \pm 0.8$ (range 3.66-7.94). The mean value of BNP was significantly higher for women compared to men, while no differences were found according to the presence of diabetes mellitus, renal failure, or coronary artery bypass graft (see Table 2). There was a mild but significant association between BNP and patient's age (Pearson's coefficient $=0.302, p<0.001$, while length of hospital stay was not associated with BNP (Pearson's coefficient $=-0.99, \mathrm{p}$ $=0.273$ ).

\section{BNP and echocardiographic parameters}

The mean LVEF was $59 \pm 10 \% ; 108$ patients $(87 \%)$ had a $\mathrm{LVEF} \geq 50 \%$. Mean $\ln (\mathrm{BNP})$ levels and $\mathrm{E} / \mathrm{E}^{\prime}$ were similar in patients with $\mathrm{LVEF} \geq 50 \%$ compared to patients with LVEF $<50 \%$ (Table 3 ). The echocardiographic parameters
Table 2: Mean value of $\ln (B N P)$ according to female gender, presence of renal failure, diabetes mellitus, and coronary artery by-pass surgery (CABG).

\begin{tabular}{lccr}
\hline & N (\%) & Mean (SD) & P value \\
\hline Female gender & $41(33)$ & $5.76(0.80)$ & \\
\hline & & & 0.032 \\
\hline Male gender & $83(67)$ & $5.44(0.79)$ & \\
\hline
\end{tabular}

Diabetes mellitus, yes $\quad 30(24) \quad 5.71(0.77)$

0.197

\begin{tabular}{lll}
\hline Diabetes mellitus, no & $94(76) \quad 5.49(0.8 \mathrm{I})$ \\
\hline
\end{tabular}

\begin{tabular}{lll}
\hline Renal failure, yes & $18(15)$ & $5.71(0.96)$ \\
\hline 0.358 & & \\
\hline Renal failure, no & $106(85)$ & $5.52(0.78)$ \\
\hline
\end{tabular}

\begin{tabular}{lll}
\hline & & \\
\hline CABG & & \\
\hline 0.312 & $54)$ & \\
\hline Other cardiac surgery & $57(46)$ & $5.47(0.76)$ \\
\hline & & \\
\hline Total & & \\
\hline
\end{tabular}

of the study group are presented in Table 4. There was no correlation between $\ln (\mathrm{BNP})$ and $\mathrm{LV}$ volumes, LVEF, RWT, E/A, DT. The relationship between $\ln (\mathrm{BNP})$ and E/ $\mathrm{E}^{\prime}$ values is depicted in Figure 1, showing that BNP is directly related to LV filling pressure (Pearson's coefficient: $0.36, \mathrm{p}<0.001$ ). Overall, patients with low BNP levels had low values of $\mathrm{E} / \mathrm{E}^{\prime}$ ratio [see Additional file 1], while patients with high BNP levels had the highest $\mathrm{E} / \mathrm{E}^{\prime}$ ratios [see Additional file 2]. A similar correlation was 
Table 3: Mean value of $\operatorname{In}(B N P)$ and E/E' according to the presence or absence of left ventricular systolic dysfunction.

\begin{tabular}{lccc}
\hline & LVEF $<50 \%$ & LVEF $\geq \mathbf{5 0} \%$ & \\
\hline & $(\mathbf{n}=16)$ & $(\mathbf{n}=108)$ & \\
\hline $\ln (\mathrm{BNP})$ & $5.4 \pm 0.5$ & $5.5 \pm 0.8$ & n.s. \\
\hline & & & \\
\hline E/E' & & & n.s. \\
\hline
\end{tabular}

found between $\ln (\mathrm{BNP})$ and LV mass (Pearson's coefficient $0.25, \mathrm{p}=0.006$ ) (Figure 2), and, albeit weaker, between $\ln (\mathrm{BNP})$ and ${ }_{\mathrm{i}} \mathrm{LAV}$ (Pearson's coefficient 0.2, $\mathrm{p}=$ 0.026 ) (Figure 3 ). However, when entered into a multiple regression model, age and $\mathrm{E} / \mathrm{E}^{\prime}$ remained the only independent predictors of BNP levels (Table 5).

\section{Discussion}

Elevated BNP levels have been previously reported both prior to and immediately after cardiac surgery. Such findings have been associated with cardiac complications, prolonged hospital stay, and 1-year mortality $[8,14,15]$. However, the reasons for BNP increase in this clinical setting have not been clarified yet, with BNP inconsistently associated with a variety of factors related to surgery, such as biomarkers of myocardial damage, anaesthesia, sternotomy, etc [16]. Since BNP increase reflects hemody- namic changes, we believe that the ultimate reason for BNP increase in these patients could be the loading changes that occur during and after cardiac surgery. Thus, we hypothesized that elevated LV filling pressures might be the trigger for BNP release.

The main findings of the present study can be summarized as follows:

1. the vast majority of post-cardiac surgery patients show a significant increase in BNP levels;

2. the increase in BNP levels does not correlate with LV systolic function;

3. E/E' ratio, an echocardiographic marker of filling pressures, is strongly associated with elevated BNP levels.

\section{BNP and ventricular function}

In patients with heart failure, plasma BNP levels are inversely related to LV systolic function [17]. In contrast, in our study population we did not find any correlation between BNP levels and systolic LV function as evaluated by echocardiographic ejection fraction. This finding is not surprising, since in the study group, which represents consecutive patients admitted to our Center, the prevalence of LV systolic dysfunction is rather low (only 3 patients had a LVEF $<40 \%$ ). Although our population was not selected, this might not represent the whole spectrum of post cardiac surgery patients.

Table 4: Echocardiographic parameters in the study group.

\begin{tabular}{llll}
\hline Parameter & Mean \pm SD & Pearson's coefficient & P value \\
\hline LVDV $(\mathrm{ml})$ & & & 0.015 \\
\hline LVSV $(\mathrm{ml})$ & $80.4 \pm 32.3$ & 0.070 & 0.507 \\
\hline LVEF $(\%)$ & $34.8 \pm 21.3$ & 0.11 & 0.006 \\
\hline LV mass $\left(\mathrm{g} / \mathrm{m}^{2.7}\right)$ & $59 \pm 10$ & -0.15 & 0.50 \\
\hline RWT & $57.3 \pm 18.3$ & 0.25 & $=0.026$ \\
\hline iLA volume $\left(\mathrm{ml} / \mathrm{m}^{2}\right)$ & $0.48 \pm 0.10$ & 0.061 & 0.772 \\
\hline E/A & $31.2 \pm 10.7$ & 0.2 & 0.336 \\
\hline DT $(\mathrm{msec})$ & $1.06 \pm 0.34$ & -0.028 & $<0.001$
\end{tabular}


Table 5: Multivariable linear regression for $\ln (B N P)$ as dependent variable (covariates: E/E', age, LV mass, LVEF, ${ }_{i}$ LAV, gender).

\begin{tabular}{lllll}
\hline Variable & Regression coefficient & $95 \% \mathbf{C l}$ & Standardized coefficient & P value \\
\hline E/E' & 0.068 & & & 0.011 \\
\hline Age, yrs & 0.018 & $0.016-0.119$ & 0.256 & 0.015 \\
\hline LV mass & 0.006 & $0.003-0.032$ & 0.2220 & 0.101 \\
\hline LVEF & -0.011 & $-0.001-0.014$ & 0.147 & 0.134 \\
\hline LAV & 0.003 & $-0.025-0.003$ & -0.025 & 0.410 \\
\hline Gender & -0.012 & $-0.005-0.011$ & 0.075 & 0.941 \\
\hline Model & $R^{2}=0.222$ & $-0.330-0.306$ & 0.007 & $<0.001$ \\
\hline
\end{tabular}

More recently, in patients with heart failure, an increase in BNP levels has also been related to diastolic (dys)function $[4,18]$. To this aim, most studies have used conventional echocardiographic parameters, such as mitral inflow diastolic velocities. However, in patients with preserved LV systolic function, i.e. the vast majority of those included in our study, the diagnostic value of these parameters is rather limited and newer echocardiographic

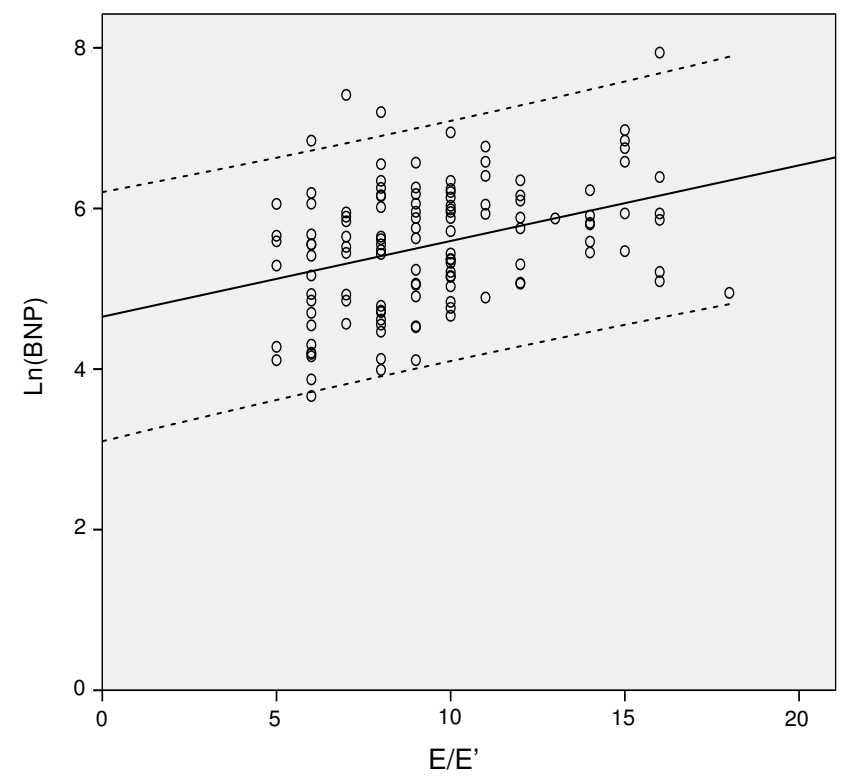

\section{Figure I}

Correlation analysis of $\ln (B N P)$ vs E/E' ratio. Circles represent individual values of brain natriuretic peptide. The black line represents the linear regression curve fit and the dotted lines its $95 \%$ confidence interval. modalities are warranted for a comprehensive categorization of the patient's hemodynamic profile. Doppler myocardial velocities at the mitral annulus are widely used for a (relatively) load-independent evaluation of diastolic properties, and left atrial volume is increasingly considered as a long-term biomarker of average LV diastolic pressure [19].

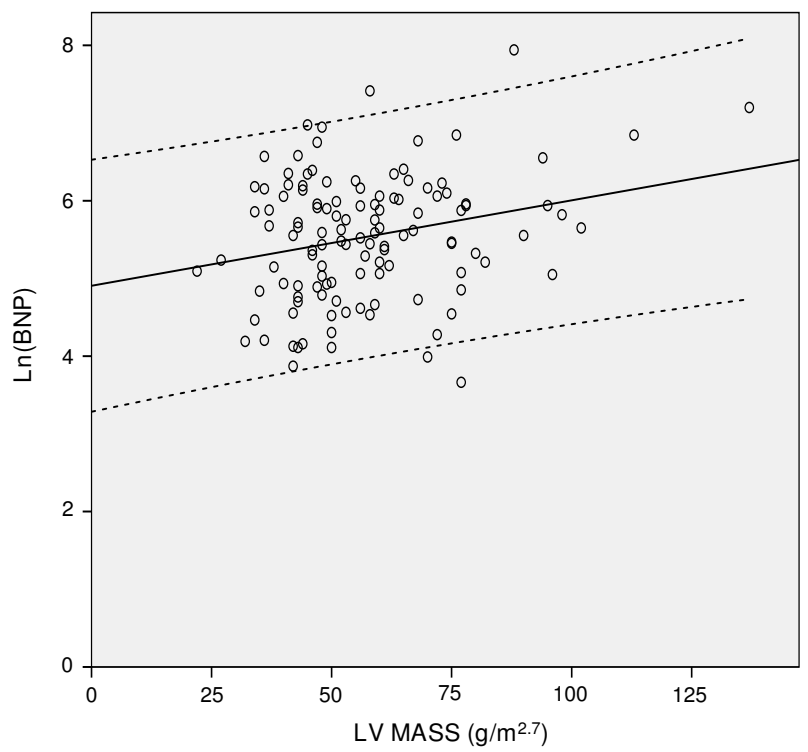

Figure 2

Correlation analysis of In(BNP) vs left ventricular (LV) mass. Circles represent individual values of brain natriuretic peptide. The black line represents the linear regression curve fit and the dotted lines its $95 \%$ confidence interval. 


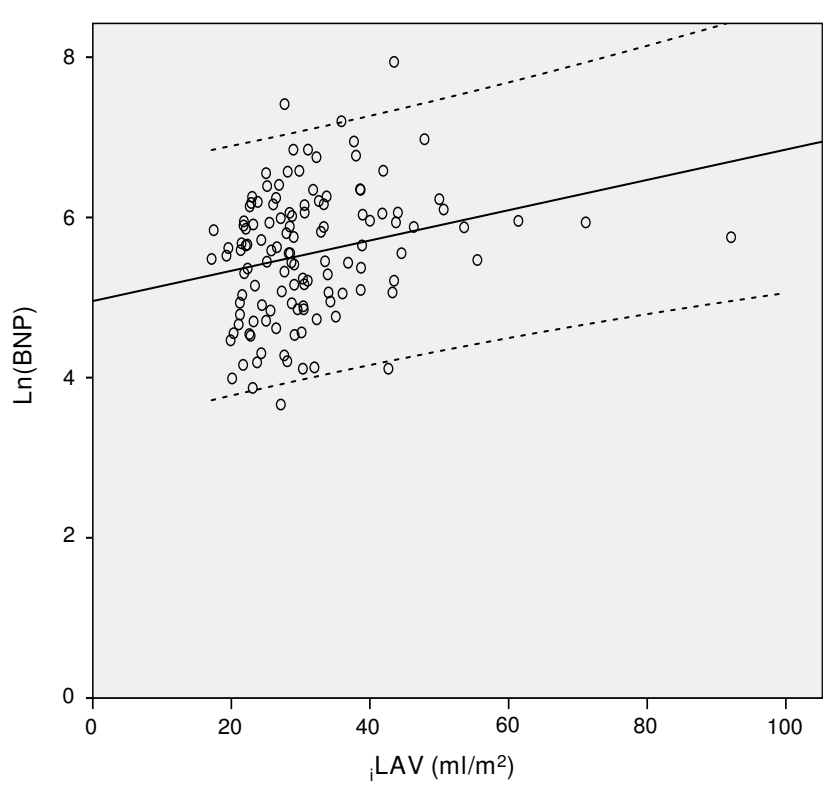

Figure 3

Correlation analysis of $\ln (B N P)$ vs indexed left atrial volume (iLAV). Circles represent individual values of brain natriuretic peptide. The black line represents the linear regression curve fit and the dotted lines its $95 \%$ confidence interval.

BNP and newer echocardiographic parameters of diastolic dysfunction

$E / E '$ ratio as an index of $L V$ filling pressures

Several studies have evaluated the relationship between BNP levels and the E/E' ratio in different clinical settings (ambulatory patients,[20] heart failure[21]), with consistent results that demonstrate a relationship between BNP levels and echocardiographic indices of LV filling pressures. The findings of the present study obtained in postcardiac surgery patients are in line with those from previous reports in different clinical settings: we observed a significant correlation between BNP levels and the E/E' ratio, indicating elevated filling pressures as the major determinant of BNP release.

Left atrium as an index of chronic diastolic dysfunction

During diastole, the left atrium is directly exposed to LV pressures. Abnormal LV diastolic function causes an elevation of filling pressures, which may lead to left atrial dilatation over time. In the present study, ${ }_{i} \mathrm{LAV}$ is associated with BNP values, however when entered into a multivariable regression analysis this parameter did not retain its statistical power as predictor of BNP levels.

\section{Additional factors affecting BNP levels}

Age, female gender, and renal failure are all variables related to BNP levels $[22,23]$. In our study, a statistically significant direct relationship between BNP levels and patient age was observed. In contrast, the difference in BNP values according to renal function, although present, was not significant perhaps because of the small sample size of our study population and the exclusion of patients on haemodialysis.

\section{Study limitations}

There are several limitations of our study. First, BNP levels before cardiac surgery were not sampled. Thus, we cannot exclude that at least in some patients BNP levels had been elevated before surgery. Secondly, we did not perform any invasive hemodynamic tests to evaluate the relationship between hemodynamic status and BNP levels. Previous studies have already shown a close correlation between BNP levels and LV end-diastolic pressure. Thirdly, we did not evaluate the impact of cardioplegic arrest on BNP levels. Finally, follow-up data that may show if elevated BNP levels are associated with worse clinical outcome are lacking. Although length in-hospital stay was independent from BNP levels, the potential role of BNP levels for longterm prognostication of post cardiac surgery patients remains to be assessed.

\section{Conclusion}

What is, then, the clinical relevance of this study? We believe that early after cardiac surgery an increase in LV filling pressure is very likely to occur, independent from LV systolic function, and is a trigger for a significant BNP release. In this clinical setting Doppler echocardiogram is a good alternative to BNP samples for assessing LV filling pressures, and E/E' in particular is a practical and more convenient parameter for detecting and monitoring haemodynamic imbalance.

\section{Competing interests}

The authors declare that they have no competing interests.

\section{Authors' contributions}

AS designed the study, interpreted the data and wrote the manuscript. EC participated in the design of the study, interpreted the data and drafted the manuscript. MP analysed the data and revised the manuscript critically. GP analysed the data and revised the manuscript critically. AP and EA reviewed the echocardiograms, performed the measurements and revised the manuscript critically. SLC performed the statistical analysis and revised the manuscript critically. SB revised the manuscript critically and his criticism was very helpful. WAAM revised the manuscript critically and his criticism was very helpful. All Authors read and approved the final manuscript. 


\section{Additional material}

\section{Additional file 1}

Echocardiographic data of a patient with normal BNP. The data provided represent two-dimensional images and Doppler samples of a 65-year old man after coronary artery bypass graft. In this patient, E/E' was 5.7, consistent with normal LV filling pressures, and BNP levels were normal $(64 \mathrm{pg} / \mathrm{ml})$.

Click here for file

[http://www.biomedcentral.com/content/supplementary/14767120-7-49-S1.pdf]

\section{Additional file 2}

Echocardiographic data of a patient with high BNP. The data provided represent two-dimensional images and Doppler samples of a 64-year old man after surgery for ascending aorta aneurysm. In this case, E/E' was 16.4, suggesting elevated LV filling pressures, and BNP levels were significantly elevated $(855 \mathrm{pg} / \mathrm{ml})$.

Click here for file

[http://www.biomedcentral.com/content/supplementary/14767120-7-49-S2.pdf]

\section{Acknowledgements}

We thank Mrs Paola Luciolli for her help and support to reviewing the English manuscript.

\section{References}

I. Morrison LK, Harrison A, Krishnaswamy P, Kazanegra R, Clopton P, Maisel AS: Utility of a rapid B-natriuretic peptide (BNP) assay in differentiating CHF from lung disease in patients presenting with dyspnea. J Am Coll Cardiol 2002, 9:202-9.

2. Wei T, Zeng C, Chen L, Chen O, Zhao R, Lu G, Lu C, Wang L: Bedside tests of $B$-type natriuretic peptide in the diagnosis of left ventricular diastolic dysfunction in hypertensive patients. Eur J Heart Fail 2005, 7:75-79.

3. De Lemos JA, Morrow DA: Use of natriuretic peptides in clinical decision-making for patients with non-ST-elevation acute coronary syndromes. Am Heart J 2007, I 53:450-3.

4. Mair J, Friendl W, Thomas S, Puschendorf B: Natriuretic peptides in assessment of left-ventricular dysfunction. Scand J Clin Lab Invest Suppl 1999, 230: 132-42.

5. Lubien E, DeMaria A, Krishnaswamy P, Clopton P, Koon J, Kazanegra R, Gardetto N, Wanner E, Maisel AS: Utility of B-natriuretic peptide in detecting diastolic dysfunction: comparison with Doppler velocity recordings. Circulation 2002, I 05:595-60I.

6. Yu CM, Sanderson JE, Shum IO, Chan S, Yeung LY, Hung YT, Cockram CS, Woo KS: Diastolic dysfunction and natriuretic peptides in systolic heart failure. Higher ANP and BNP levels are associated with the restrictive filling pattern. Eur Heart J 1996, | 7:1694-702.

7. Kruger S, Graf J, Kunz D, Stickel T, Hanrath P, Janssens U: Brain natriuretic peptide levels predict functional capacity in patients with chronic heart failure. J Am Coll Cardiol 2002, 40:718-22.

8. Hutfless R, Kazanegra R, Madani M, Bhalla MA, Tulua-Tata A, Chen A, Clopton P, James C, Chiu A, Maisel AS: Utility of B-type natriuretic peptide in predicting postoperative complications and outcomes in patients undergoing heart surgery. J Am Coll Cardiol 2004, 43: 1873-9.

9. Neverdal NO, Knudsen CW, Husebye T, Vengen OA, Pepper J, Lie $M$, Tønnessen $T$ : The effect of aortic valve replacement on plasma B-type natriuretic peptide in patients with severe aortic stenosis - one year follow-up. Eur J Heart Fail 2006, 8:257-262.

10. Avidan MS, Meehan N, Ponte J, El-Gamel A, Sherwood RA: Changes in brain natriuretic peptide concentrations following open cardiac surgery with cardioplegic arrest. Clin Chim Acta 200I, 303:127-32

II. Rawlins ML, Owen WE, Roberts WL: Performance characteristics of four automated natriuretic peptide assays. $\mathrm{Am} J \mathrm{Clin}$ Pathol 2005, I 23:439-45.

12. Lang RM, Bierig M, Devereux RB, Flachskampf FA, Foster E, Pellikka PA, Picard MH, Roman MJ, Seward J, Shanewise J, Solomon S, Spencer KT, St John Sutton M, Stewart W, American Society of Echocardiography's Nomenclature and Standards Committee; Task Force on Chamber Quantification; American College of Cardiology Echocardiography Committee; American Heart Association, European Association of Echocardiography, European Society of Cardiology: Recommendations for chamber quantification. Eur J Echocardiogr 2006, 7:79-108.

13. Ommen SR, Nishimura RA, Appleton CP, Miller FA, Oh JK, Redfield MM, Tajik AJ: Clinical utility of Doppler echocardiography and tissue doppler imaging in the estimation of left ventricular filling pressure. Circulation 2000, 102: I 788-1794.

14. Kerbaul F, Collart F, Giorgi R, Oddoze C, Lejeune PJ, Guidon C, Caus $T$, Bellezza M, Gouin F: Increased plasma levels of pro-brain natriuretic peptide in patients with cardiovascular complications following off-pump coronary artery surgery. Intensive Care Med 2004, 30:1799-806.

15. Berendes E, Schmidt C, Van Aken H, Hartlage MG, Rothenburger M, Wirtz S, Scheld HH, Brodner G, Walter M: A-type and B-type natriuretic peptide in cardiac surgical procedures. Anesth Analg 2004, 98: II-9.

16. Georges A, Forestier F, Valli N, Plogin A, Janvier G, Bordenave L: Changes in type $B$ natriuretic peptide (BNP) concentrations during cardiac valve replacement. Eur Cardiothorac Surg 2004, 25:94I-5.

17. Muders F, Kromer EP, Griese DP, Pfeifer M, Hense HW, Riegger GA, Elsner D: Evaluation of plasma natriuretic peptides as markers for left ventricular dysfunction. Am Heart J 1997, I 34:442-9.

18. Grewal J, McKelvie R, Lonn E, Tait P, Carlsson J, Gianni M, Jarnert C, Persson H: BNP and NT-proBNP predict echocardiographic severity of diastolic dysfunction. Eur J Heart Fail 2008, 10:252-259.

19. Douglas PS: The left atrium. A biomarker of chronic diastolic dysfunction and cardiovascular disease risk. I Am Coll Cardiol 2003, 42: 1206-7.

20. Dong S], de las Fuentes L, Brown AL, Waggoner AD, Ewald GA, Davila-Roman VG: $\mathbf{N}$-terminal pro B-type natriuretic peptide levels: correlation with echocardiographically determined left ventricular diastolic function in an ambulatory cohort. I Am Soc Echocardiogr 2006, 19:1017-25.

21. Troughton RW, Prior DL, Pereira J], Martin M, Fogarty A, Morehead A, Yandle TG, Richards AM, Starling RC, Young JB, Thomas JD, Klein $A L$ : Plasma B-type natriuretic peptide levels in systolic heart failure: importance of left ventricular diastolic function and right ventricular systolic function. J Am Coll Cardiol 2004, 43:416-22.

22. Redfield MM, Rodeheffer RJ, Jacobsen SJ, Mahoney DW, Bailey KR, Burnett JC Jr: Plasma brain natriuretic peptide concentration: impact of age and gender. J Am Coll Cardiol 2002, 40:976-82.

23. Cataliotti $A$, Malatino LS, Jougasaki $M$, Zoccali $C$, Castellino $P$, Giacone G, Bellanuova I, Tripepi R, Seminara G, Parlongo S, Stancanelli B, Bonanno G, Fatuzzo P, Rapisarda F, Belluardo P, Signorelli SS, Heublein DM, Lainchbury JG, Leskinen HK, Bailey KR, Redfield $M M$, Burnett JC Jr: Circulating natriuretic peptide concentrations in patients with end-stage renal disease: role of brain natriuretic peptide as a biomarker for ventricular remodeling. Mayo Clin Proc 200 I, 76: I I I I-9. 